\title{
Use of a Fluorinated Probe to Quantitatively Monitor Amino Acid Binding Preferences of Ruthenium(II) Arene Complexes
}

\author{
George S. Biggs, ${ }^{\dagger}$ Michael J. O’Neill, ${ }^{\dagger}{ }^{\ddagger}$ Pablo Carames Mendez, Thomas G. Scrase, Yulu
} Lin, Amzar Muzani Bin-Maarof, Andrew D. Bond, Sally R. Boss* and Paul D. Barker*

University of Cambridge, Chemistry Department, Lensfield Road, Cambridge CB2 1EW, UK

$\ddagger$ Faculty of Science and Engineering School of Mathematics and Physical Sciences, University of Hull, Hull, UK

${ }^{\dagger}$ These authors contributed equally to this project.

\section{ABSTRACT:}

In order to address outstanding questions about ruthenium complexes in complex biological solutions, ${ }^{19} \mathrm{~F}$ NMR spectroscopy was used to follow the binding preferences between fluorinated $\mathrm{Ru} \mathrm{u}^{\prime \prime}\left(\eta^{6}\right.$-arene)(bipyridine) complexes and protected amino acids and glutathione. Reporting what ruthenium compounds bind to in complex environments has so far been restricted to relatively qualitative methods, such as mass spectrometry and Xray spectroscopic methods; however, quantitative information on the species present in the solution phase cannot be inferred from these techniques. Furthermore, using ${ }^{1} \mathrm{H} N M R$, in water, to distinguish and monitor a number of different complex $\mathrm{Ru}^{11}\left(\eta^{6}\right.$-arene) adducts forming is challenging. Incorporating an NMR active heteroatom into ruthenium organometallic complexes provides a quantitative, diagnostic 'fingerprint' to track solutionphase behaviour and allow for unambiguous assignment of any given adduct. The resulting ${ }^{19} \mathrm{~F}$ NMR spectra show for the first time the varied, dynamic behaviour of organoruthenium compounds when exposed to simple biomolecules in complex mixtures. The rates of formation of the different observed species are dramatically influenced by the electronic properties at the metal, even in a closely related series of complexes in which only the electron-donating properties of the arene ligand are altered. Preference for cysteine binding is absolute: the first quantitative solution-phase evidence of such behaviour.

\section{INTRODUCTION:}

One motivation for using ruthenium in medicinal compounds is to introduce a drug-target interaction for which the bonding energy is between that of true non-covalent intermolecular interactions and a covalent bond..$^{1-3}$ In principle, tuning the strength of a metal-target coordination bond could be used to control the dissociation rate of a drugtarget interaction in a way that is orthogonal to that provided by conventional medicinal chemistry. Consequently, a raft of studies have begun to explore the binding preferences of simple ruthenium organometallic complexes for biomolecular targets, with many of these compounds demonstrating promising anticancer activity. ${ }^{4-6}$

The ruthenium complexes that have entered clinical trials, NAMI-A and KP1019 have received significant attention with respect to their distributions within plasma and in cells. They are characterized by having a number of ligands we would class as exchangeable in aqueous solution on a timescale relevant to cellular processes. These complexes are very promiscuous in complex biological mixtures, with little understanding of their modes of action or final cellular speciation. ${ }^{7-9}$ 
Ruthenium(II) arene complexes incorporating a wide range of different ligands have also been studied extensively in this context. ${ }^{10-16}$ In comparison with $\mathrm{Ru}^{\mathrm{III}}$ complexes, the $\mathrm{Ru}^{\prime \prime}\left(\eta^{6}\right.$-arene) bioactive scaffold has led to increased control over the biomolecular targets of ruthenium complexes. RAPTA-type complexes, $\left[\mathrm{Ru}(\right.$ arene $\left.)(\mathrm{PTA}) \mathrm{X}_{2}\right]$ preferentially bind to proteins ${ }^{17,18}$ whereas RAED-type complexes $[\mathrm{Ru}($ arene $)(\mathrm{en}) \mathrm{Cl}]$ (en $=1,2$ ethylenediamine) preferentially bind to DNA; this binding can be enhanced through extended $\pi$-systems. ${ }^{19,20}$ Although these complexes have shown promising anticancer activity, they are still highly promiscuous and there is little insight into their complete cellular speciation.

The dynamic nature of the cellular concentrations and accessibility of biomolecules combined with the characteristically slow ligand exchange rates associated with $\mathrm{Ru}(\mathrm{II})$ arene complexes ${ }^{21}$ makes understanding the relationship between speciation of the metal complexes and cellular response problematic. A direct read out of what the ruthenium compounds are bound to in biological environments remains challenging and has so far been restricted to relatively qualitative methods, such as mass spectrometry ${ }^{22-24}$ and X-ray spectroscopic methods. ${ }^{25-27}$

NMR spectroscopy is a quantitative, sensitive, direct reporter for solution behaviour. However, using 1-Dimensional ${ }^{1} \mathrm{H}$ NMR to follow the speciation of ruthenium complexes has proved testing for anything other than the simplest examples. The large number of observable proton signals together with their chemical similarity and hence proximity in the spectra severely restricts the usefulness of ${ }^{1} \mathrm{H}$ NMR in this context. 2-Dimensional NMR experiments can overcome this complexity; however, these experiments are often time consuming, with high sample concentration necessary, if temporal resolution is required. ${ }^{31} \mathrm{P}$ NMR has been used extensively for following the metabolic state of phosphate esters in vivo. ${ }^{28-30}{ }^{15} \mathrm{~N}$ and ${ }^{13} \mathrm{C}$ are commonly used to examine the structure and dynamics of proteins in vivo. ${ }^{31}$

${ }^{19} \mathrm{~F}$ NMR can also be used as a sensitive probe of specific metabolic signals when a fluorine atom can be incorporated into a small or large biomolecule as a reporter. ${ }^{32,33}$ The use of ligand-based fluorine NMR screening methods to rapidly identify biologically active fluorinated organic compounds has demonstrated the usefulness of being able to detect a ${ }^{19} \mathrm{~F}$ NMR signal in complex environments. ${ }^{34,35}$

Furthermore, incorporating fluorine atoms into lead drug compounds, has proven to be a popular way to improve the pharmacological properties of organic-based drugs, with approximately $20 \%$ of all currently available drugs on the market containing at least one fluorine atom. ${ }^{34}$ Recently, a fluoride ligand has been incorporated into the axial position of a Pt(IV) anticancer pro-drug to enhance stability and cytotoxicity. ${ }^{36}$ Therefore, we believe that incorporating fluorine substituents into $\mathrm{Ru}^{\prime \prime}$ arene complexes can be greatly beneficial in probing their reactivity in complex mixtures, as well as a means of altering activity.

Throughout this study, we have used ${ }^{19} \mathrm{~F}$ NMR to gather quantitative information, such as kinetic parameters and percentage formation of the species present in solution, with mass spectrometry used to support the assignment of species. This combined approach can greatly simplify observing the binding preferences of $\mathrm{Ru}(\mathrm{II})$ arene in complex biological mixtures. The purpose here, was not to develop a new bioactive ruthenium organometallic compounds, but to explore a quantitative spectroscopic method for quickly and accurately assigning the speciation of ruthenium organometallics in complex solutions. 
Table 1: Complexes synthesized and studied in this work, isolated and used as the hexafluorophosphate salts.

\begin{tabular}{|c|c|c|c|}
\hline \multirow{13}{*}{ (1) } & Complex & Ar-X & $\begin{array}{c}\text { Bipyridyl } \\
\text { substituents } \\
\text { R }\end{array}$ \\
\hline & 1 & Benzene & 5,5'-difluoro \\
\hline & 2 & Toluene & 5,5'-difluoro \\
\hline & 3 & $p$-Cymene & 5,5'-difluoro \\
\hline & 4 & $\begin{array}{l}\text { Hexameth- } \\
\text { ylbenzene }\end{array}$ & 5,5'-difluoro \\
\hline & 5 & Benzene & 3,3'-difluoro \\
\hline & 6 & Toluene & 3,3'-difluoro \\
\hline & 7 & $p$-Cymene & 3,3'-difluoro \\
\hline & 8 & $\begin{array}{l}\text { Hexameth- } \\
\text { ylbenzene }\end{array}$ & 3,3'-difluoro \\
\hline & 9 & Benzene & 6,6'-difluoro \\
\hline & 10 & Benzene & 5,5'-di(trifluoromethyl) \\
\hline & 11 & Benzene & none (all $\mathrm{H}$ ) \\
\hline & 12 & $p$-Cymene & none (all H) \\
\hline
\end{tabular}

Incorporating the fluorine atoms into a bipyridyl ligand, which is stable to dissociation, enabled at least two fluorines in chemically similar environments to be introduced to each complex. We synthesised four fluorinated 2,2'-bipyridyl derivatives; 3,3', 5,5', 6,6'-difluoro and 5,5'-trifluoromethyl. To counteract the electron withdrawing effect of the fluorinated ligands on the metal, we also varied the arene ligand, including more electron-donating substituted arenes by way of compensation. The full set of complexes reported is listed in Table 1, and Figure S1.

Some of these complexes provide excellent sensitivity to the metal coordination environment and dispersion of signals that have allowed us to resolve the surprising number of different species present. The sensitivity we report suggests that this approach could be developed for use in vivo and we have made attempts to test that. We also show that the rates of formation of different species are dramatically influenced by the electronic properties at the metal, even in a closely related series of complexes in which only the electron-donating properties of the arene ligand are altered.

\section{RESULTS AND DISCUSSION}

A number of literature preparations are available for the preparation of functionalised bipyridines, ${ }^{37,38}$ however, after achieving relatively poor yields using copper catalysed, Ullman-type coupling reactions, the fluorinated bipyridines were synthesised using an adapted palladium-catalysed homocoupling procedure in poly(ethylene) glycol (see Experimental Section). ${ }^{39}$ We found that all except the 4,4'-difluorobipyridyl derivative could be made reliably in good yield; we have not pursued the $4,4^{\prime}$ derivative any further. The synthesis of the ruthenium complexes [1] - [12] was achieved by reacting the appropriate ruthenium arene dimer with a stoichiometric amount of the chosen bipyridyl derivative. These complexes were characterised by NMR, ESI-MS, elemental analysis and X-ray diffraction.

Single crystals suitable for X-ray diffraction for complexes [1] - [10] were grown via slow diffusion of diethyl ether into a saturated solution of the complex in acetone. The X-ray crystallographic data for all complexes are given in Tables S2-4. The novel complexes [1][10] adopt a pseudo-octahedral piano stool configuration. A representative analysis of key bond lengths and angles for the 5,5'-fluorinated bipyridine series is summarised in Table S1. Complexes [1] and [2] have shorter Ru-Cl bond lengths than complexes [3] and [4] 
which could provide a hint towards the lability of the chloride when other nucleophiles are present, but these small differences cannot be used to inform solution based behavior.

\section{Speciation in Aqueous Solutions}

Before exposing the ruthenium complexes to biomolecules, they were monitored in deuterated phosphate buffer, $\mathrm{pD}=7.2$ and $1 \%$ DMF which leads to an equilibrium between chloro, aquo and phosphate adducts, Figure 1a. In order to be able to see as many relevant species as possible, high concentrations of the complexes under study were needed so a small amount of DMF was used, to enhance solubility. We have seen no evidence of DMF coordinating under these conditions. For the fluorinated complexes [1] - [8] and [10], three singlet peaks are observed in the ${ }^{19} \mathrm{~F}$ NMR spectra, as represented in Figure 1b. The behaviour of complex [9], the 6,6'-bipyridyl derivative, was significantly different suggesting that the proximity of the fluorines to the metal impacted upon the ligand exchange properties. For [11]-[12], ${ }^{1} \mathrm{H}$ NMR spectra were used to resolve the speciation through the diagnostic metal-coordinated arene signals. ${ }^{40}$

a)
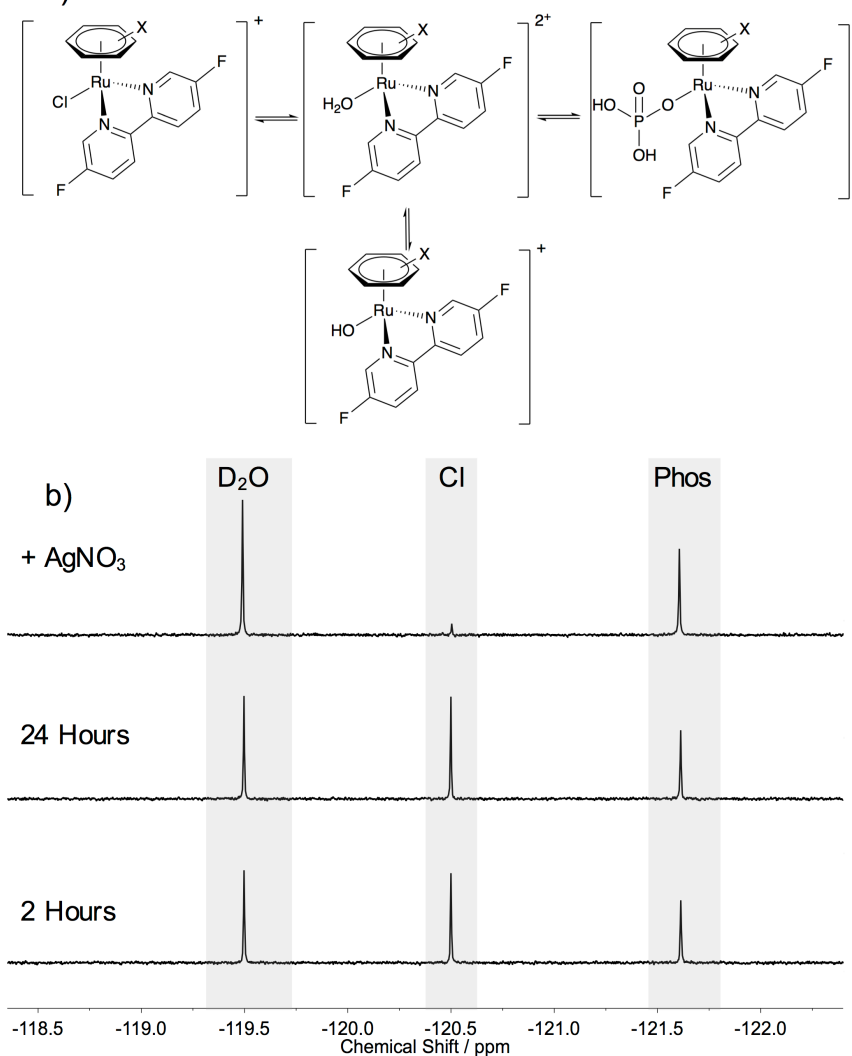

c)

$\mathrm{D}_{2} \mathrm{O}$

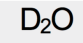

Cl Phos

$10 \mathrm{mM} \mathrm{D} \mathrm{O}$

Phosphate

$100 \mathrm{mM} \mathrm{D}_{2} \mathrm{O}$

Phosphate

d)
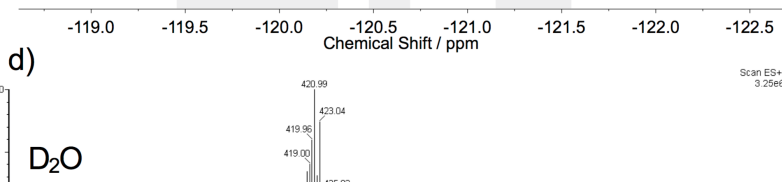

$\mathrm{D}_{2} \mathrm{O}$

$10 \mathrm{mM} \mathrm{D} 2 \mathrm{O}$

Phosphate

$10 \mathrm{mM} \mathrm{D}_{2} \mathrm{O}$

Phosphate

Figure 1: Figure 1a: The equilibria that exist when $\left[R u\left(\eta^{6} \text {-arene }\right)\left(5,5^{\prime} \text {-difluorobipyridine }\right)\right]^{+}$ complexes are incubated in phosphate buffer. Figure $1 \mathrm{~b}$ : Time course ${ }^{19} \mathrm{~F}\left\{{ }^{1} \mathrm{H}\right\}$ NMR spectra of complex [4] incubated in $10 \mathrm{mM}$ deuterated phosphate buffer $(2 \mathrm{mM} \mathrm{Ru}, \mathrm{pD}=$ 7.2, $310 \mathrm{~K}$ ). After $24 \mathrm{hr}, 1$ eq. of $\mathrm{AgNO}_{3}$ was added to abstract the chloride ligand and encourage formation of the aquo complex. Figure 1c: ${ }^{19} \mathrm{~F}\left\{{ }^{1} \mathrm{H}\right\}$ NMR spectra of complex [2] incubated in $\mathrm{D}_{2} \mathrm{O}$ and buffered $\mathrm{D}_{2} \mathrm{O}$ of different phosphate concentration $(2 \mathrm{mM} \mathrm{Ru}, \mathrm{pD}=$ 7.2 (when buffered), $2 \mathrm{hr}, 310 \mathrm{~K}$ ). Figure 1d: Mass spectra recorded of the solution mixture when complex [2] is incubated in $\mathrm{D}_{2} \mathrm{O}$ and buffered $\mathrm{D}_{2} \mathrm{O}$, expected masses quoted in Table S6. 
With a number of titratable groups involved in these systems, examining the ligand exchange behaviour of these complexes around conditions of $\mathrm{pH}$ relevant to biological conditions requires strong buffering. We chose phosphate as a buffer also for its relevance to biological conditions. However, it is clear that phosphate competes quite strongly as a ligand to the metal, Figure 1c, and the presence of phosphate species have been confirmed by mass spectrometry, Figure 1d and Table S6. Sadler et al. showed that the structurally related $\left[\mathrm{Ru}\left(\eta_{6} \text {-arene }\right)(\mathrm{en}) \mathrm{Cl}\right]^{+}$initially binds to the phosphate in the nucleobase 5-GMP before being displaced by the guanine N7. ${ }^{41}$ To maintain a balance between buffering strength and introducing a competing ligand a phosphate buffer concentration of $10 \mathrm{mM}$ was chosen for all incubations, when the ruthenium concentration was $2 \mathrm{mM}$.

${ }^{19} \mathrm{~F}$ resonances from the aquo and phosphate species are $\mathrm{pH}$ dependent and therefore the $\mathrm{pK}_{\mathrm{a}}$ for the deprotonation of the bound aquo ligand can easily be measured. Figures $2 \mathrm{a}$, $2 \mathrm{~b}$ and $2 \mathrm{c}$ show representative data and calculated $\mathrm{pK}_{\mathrm{a}}$ values for the benzene complexes with different bipyridyls (Complexes [1], [10] and [11]) and for the 5,5 difluorobipyridyl complex with different arene ligands (Complexes [1] - [4]). The observed differences in $\mathrm{pK}_{\mathrm{a}}$ are entirely consistent with the changes in electron density at the metal due to the subtleties of the electron withdrawing effects of fluorines on the bipyridyl ligand and the electron donating effects of the different arenes. ${ }^{42}$ In other words, the trend observed going from complex [1] - [4] shows that the increasing electron donating capability of the $\eta_{6}$-arene ligand to the ruthenium centre leads to a higher measured $\mathrm{pK}_{\mathrm{a}}$ value; an increased electron density on the metal lowers its Lewis acidity. The electron withdrawing capabilities of the trifluoromethyl group on complex [10] significantly increases the Lewis acidity, reflected in the lowest $\mathrm{pK}_{\mathrm{a}}$ measured for any of these complexes. Interestingly, pKa had to be measured using ${ }^{1} \mathrm{H}$ spectra because the ${ }^{19} \mathrm{~F}$ resonances in this complex, where the fluorine atoms are not directly on the bipyridyl ring, are not sensitive enough to changes in coordination to accurately measure the $\mathrm{pK}_{\mathrm{a}}$. Clearly this has implications for the general use of ${ }^{19} \mathrm{~F}$ on spectator ligands for reporting changes at the metal site. 


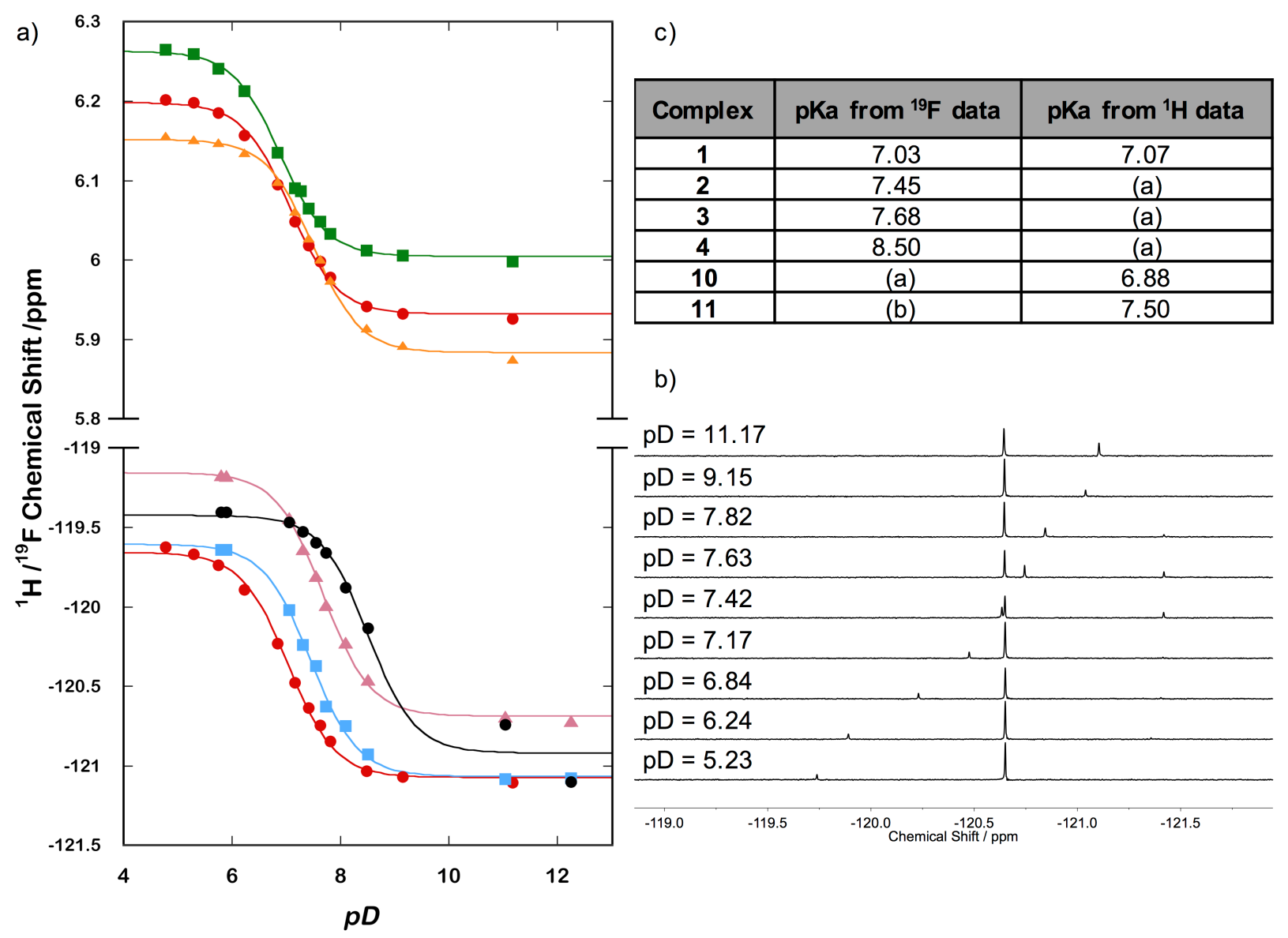

Figure 2a: $\mathrm{pH}$ dependence of the chemical shifts of the aquo coordinated ruthenium species and determination of the $\mathrm{pK}_{a}$ in the following complexes [1] - Red circles; [2] - Blue squares; [3] - Pink triangles; [4] - black circles; [10] - Green squares; [11] - Orange triangles. ${ }^{19} \mathrm{~F}$ chemical shifts of the 5,5'-difluorobipyridyl fluorines or ${ }^{1} \mathrm{H}$ chemical shift of the coordinated benzene ligand were plotted against pD. The lines are a least squares fit to an equation involving a single titratable group. Figure $2 \mathrm{~b}$ : A series of ${ }^{19} \mathrm{~F}\left\{{ }^{1} \mathrm{H}\right\}$ decoupled spectra of complex [1] in $\mathrm{D}_{2} \mathrm{O}$ phosphate buffer at differing $\mathrm{pD}$ values (2 mM Ru, $298 \mathrm{~K}$ ). Figure 2c: The $\mathrm{pK}_{\mathrm{a}}$ values of a series of ruthenium complexes measured using (where applicable) both ${ }^{19} \mathrm{~F}\left\{{ }^{1} \mathrm{H}\right\}$ NMR and ${ }^{1} \mathrm{H}$ NMR. (a) - Unable to measure $\mathrm{pK}_{\mathrm{a}}$ from data collected. (b) - No fluorine atoms present in complex.

\section{Diagnostic determination of amino acid binding}

Reaction of these probes with $\mathrm{N}$ - and/or C-protected amino acids gave a series of characteristic ${ }^{19} \mathrm{~F}$ NMR signals, allowing for unambiguous assignment of any given adduct. We note that the fluorines on the bipyridyl ring are diastereotopic and once a chiral amino acid ligand is coordinated to a ruthenium in the piano stool complex they are magnetically inequivalent. ${ }^{43}$ Therefore, despite the symmetry of the starting molecule, the amino acid coordinated adducts of these complexes don't always give rise to single resonances in the proton decoupled ${ }^{19} \mathrm{~F}$ NMR spectra.

It is therefore necessary to point out how we have interpreted the spectra and especially how the diastereotopic context of the fluorine atoms in the 5,5'-bipyridyl positions results in more complex ${ }^{19} \mathrm{~F}$ NMR spectra than one might expect. For instance, when complex [1] is incubated with $\mathrm{N}$-acetyl L-glutamine two doublets separated by $0.18 \mathrm{ppm}$ are observed, which we attribute to one species with the glutamine coordinated via the $\alpha$-carboxylate of 
the amino acid. That these signals originate from the same species is clearly evidenced by the ${ }^{8} \mathrm{~J}_{\mathrm{F}-\mathrm{F}}$ coupling of $2.26 \mathrm{~Hz}$ observed at high resolution and a clear cross-peak in a proton decoupled ${ }^{19} \mathrm{~F}-{ }^{19} \mathrm{~F}$ COSY experiment (Figure 3). When achiral amino acids (e.g. Nacetyl glycine) are coordinated through the $\alpha$-carboxylate only a singlet is observed, as expected (Figure S2).

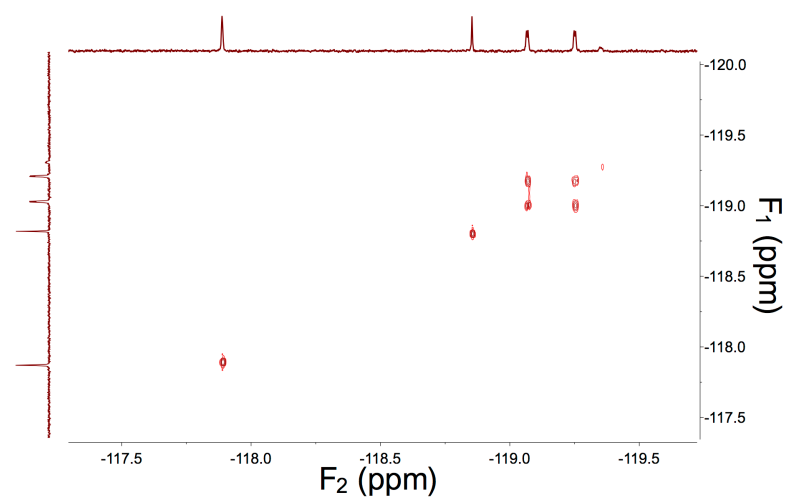

Figure 3: $A{ }^{19} \mathrm{~F}\left\{{ }^{1} \mathrm{H}\right\}-{ }^{19} \mathrm{~F}\left\{{ }^{1} \mathrm{H}\right\}$ COSY spectra from the incubation of complex [1] with $\mathrm{N}$ acetyl L-glutamine (2 mM Ru, 3 eq. amino acid, starting pD = 7.2, 24 hr, $310 \mathrm{~K}$ ).

Under similar conditions, a ruthenium species with $\mathrm{N}$-acetyl cysteine methyl ester coordinated can also give more than one peak (see Figure 4, complexes [1] $(\mathrm{Ar}=$ benzene) and [3] ( $\mathrm{Ar}=p$-cymene). In the case of complex [1], variable temperature experiments show that this really is two coupled doublets with very strong roofing (Figure S3). The chemical shift separation between the diastereotopic fluorine signals is small and consequently this peak often appears as one broad resonance. Again, achiral thiolate molecules (cystamine for instance) clearly coordinate through the sulfur and yield a sharp singlet in the proton decoupled ${ }^{19} \mathrm{~F}\left\{{ }^{1} \mathrm{H}\right\}$ spectrum (Figure S2). Additionally, the variable temperature experiments provided no indication that there is restricted rotation about the metal ligand bond that could cause an environment that breaks the symmetry (Figure S3).

However, the consequences of the diastereotopic fluorines are not always manifest in the spectra. In the case of the 3,3'-difluorobipyridyl complexes, [5] (Ar = benzene) and [7] (Ar = $p$-cymene), only one Ru-cysteine ${ }^{19} \mathrm{~F}$ NMR signal is observed, see Figure 4 . The crystal structure of the 3,3'-difluorobipyridyl containing complex, [5], shows that the organometallic ion is in fact chiral at the metal due to the adjacent fluorines being forced out of plane by each other (both enantiomers are present in the centrosymmetric crystal structure, see ESI). Should a chiral amino acid coordinate in place of the chloride, this would technically generate diastereomers. Presumably the metal-ligand coordination sphere is flexible enough in solution for there to be fluxionality between the two non-planar pyridyl rings such that the two fluorine environments appear equivalent and we observe only one ${ }^{19} \mathrm{~F}$ NMR signal, the non-chiral average. So, although coordination of the 3,3'difluorobipyridine ligand to the ruthenium piano stool should also lead to diastereotopic fluorines, they appear in the same magnetic environment and their signals do not split into two. 


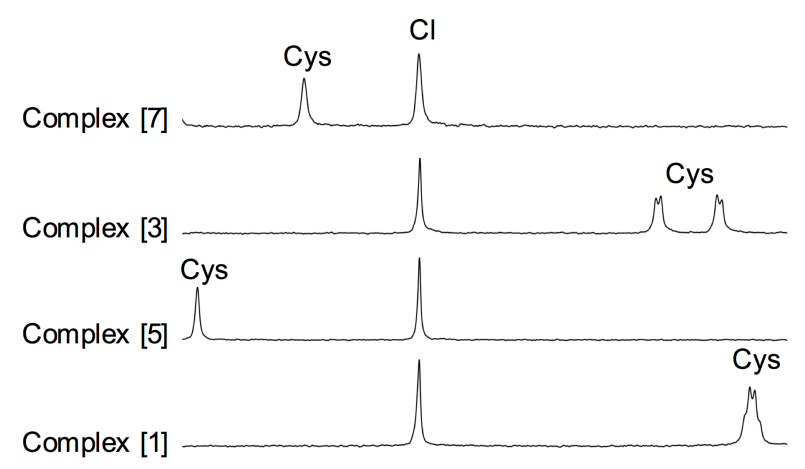

Figure 4: A series of ${ }^{19} \mathrm{~F}\left\{{ }^{1} \mathrm{H}\right\}$ NMR spectra of complexes [1], [3], [5] and [7] incubated with $\mathrm{N}$-acetyl cysteine methyl ester ( $2 \mathrm{mM} \mathrm{Ru}, 3$ eq. amino acid, $310 \mathrm{~K})$. The chemical shift scale is the same for all spectra, which are aligned to the chloride peak in each case. Absolute $\delta$ values given in Table S5.

The extra complexity in the signals observed with the fluorines in the 5,5'-bipyridyl positions reduces the sensitivity of the experiment given that we generate two ${ }^{19} \mathrm{~F}$ signals for each amino-acid coordinated ruthenium complex rather than one intense singlet. However, the sophistication in the level of detail we can observe with this technique is exemplified where the diastereotopic nature of the fluorines is apparent in the spectra. Therefore, we pursued the 5,5'-difluorobipyridyl complexes to give us the most complete understanding of the complexes under discussion but noting that the 3,3'-difluorobipyridine complexes might be more suited to further studies of more complex mixtures of species.

\section{Influence of the arene ligand on complex speciation}

The ${ }^{19} \mathrm{~F}$ NMR spectra of the 5,5'-difluorobipyridyl complexes [1] - [4] incubated with Nacetyl cysteine methyl ester, Figure 5, show the extent to which ligand exchange varies with different arene ligands. In addition, the electron donating properties of the arene ligand influence the chemical shift separation of the doublets with the hexamethylbenzene complex, [4] providing the greatest resolution.

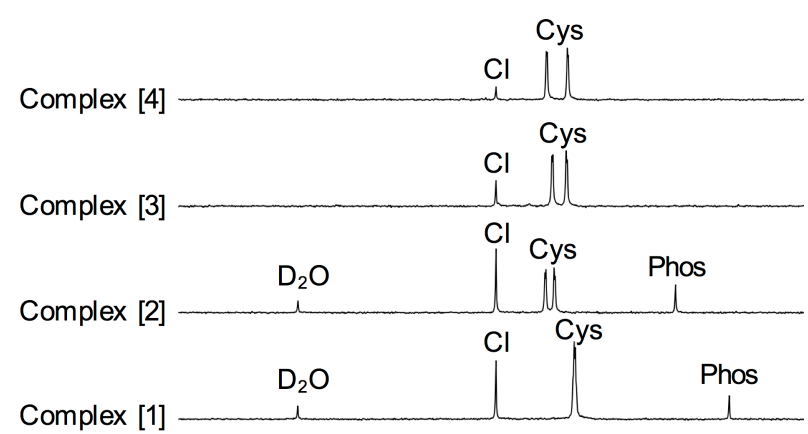

Figure 5: ${ }^{19} \mathrm{~F}\left\{{ }^{1} \mathrm{H}\right\}$ NMR spectra of complexes [1], [2], [3] and [4] incubated with N-acetyl cysteine methyl ester ( $2 \mathrm{mM} \mathrm{Ru}, 3$ eq. amino acid, $24 \mathrm{hr}, 310 \mathrm{~K}$ ). The chemical shift scale is the same for all spectra, which are aligned to the chloride peak in each case. Absolute $\delta$ values given in Table S5.

The formation of the ruthenium cysteine adducts have been measured over a short period and rate constants measured, Table 2 and Figure S4. There is an initial rapid approach to equilibrium between the chloride, aquo and phosphate species. The observed rate of cysteine complex formation is adequately described by a $1^{\text {st }}$ order process, therefore, we 
believe ligand dissociation to be the rate determining step. The benzene and tolyl complexes, [1] and [2] have comparable rate constants, however, the cymene and hexamethylbenzene complexes [3] and [4] are slightly faster, as expected, due to the increased electron donating capabilities of the cymene and hexamethylbenzene ligands.

Table 2: A comparison of the rate constants for the complexes [1] - [4] for the formation of a ruthenium cysteine adduct ( $2 \mathrm{mM} \mathrm{Ru}, 3$ eq amino acid, $310 \mathrm{~K}$ )

\begin{tabular}{|c|c|}
\hline Complex & $\mathrm{k}_{\mathrm{obs}} / \times 10^{-4} \mathrm{~s}^{-1}$ \\
\hline$[1]$ & $2.17 \pm 0.03$ \\
\hline$[2]$ & $2.08 \pm 0.05$ \\
\hline$[3]$ & $2.76 \pm 0.04$ \\
\hline$[4]$ & $3.71 \pm 0.08$ \\
\hline
\end{tabular}

A screen of complex [1] with all of the naturally-occurring amino acids with side chains suitable for metal coordination allowed us to identify those amino acids (cysteine, glutamic acid, histidine and methionine) that give detectable metal complexes at relatively low adduct concentrations. These amino acids were protected at both the amino and carboxylate ends, to limit binding to amino acid side chains, and incubated in an excess of the ruthenium complexes [1] - [4]. The chosen amino acids offer some side chain variety given that we predicted that cysteine and methionine would coordinate through sulphur, glutamic acid through oxygen and histidine through nitrogen.

These incubations were followed by ${ }^{19} \mathrm{~F}\left\{{ }^{1} \mathrm{H}\right\}$ and ${ }^{1} \mathrm{H}$ NMR, and mass spectrometry (Table S7) over a 24-hour period at $310 \mathrm{~K}$ in $10 \mathrm{mM} \mathrm{D} \mathrm{D}_{2} \mathrm{O}$ phosphate buffer with starting $\mathrm{pD}=7.2$. These temporal experiments enabled us to identify and quantify signals due to rutheniumamino acids adducts, e.g. complex [1] with cysteine, Figure S5. The data from these incubations is summarised in Table 3 for the two electronic extremes, the benzene arene, complex [1], and the hexamethylbenzene arene, complex [4]. Given that the coordination of some amino acid side chains results in a release of protons it proved difficult to clamp the $\mathrm{pD}$ tightly in the experiments described below, even with $10 \mathrm{mM}$ phosphate buffer. The exact change in $\mathrm{pD}$ of any experiments described below could be measured intrinsically from the chemical shift of the ${ }^{19} \mathrm{~F}$ signals from each specific aquo complex, which are exceptionally sensitive to changes in $\mathrm{pD}$. The greatest adduct formation is observed for both complexes [1] and [4] with N-Ac-Cysteine-OMe. Furthermore, the adduct formation with [4] is much greater for the softer side chains of cysteine, histidine and methionine.

Table 3: Reactions of complexes [1] and [4] with protected amino acids (2 mM Ru, 1.5 eq. amino acid, buffer starting $\mathrm{pD}=7.2,310 \mathrm{~K}$ ). \% reaction is calculated through integrating [Ru]-amino acid peak with respect to the peak areas of the chloride, aquo and phosphate species. $\mathrm{pD}$ is measure from the $\delta$ of the aquo species. 


\begin{tabular}{|c|c|c|c|c|c|}
\hline \multicolumn{2}{|c|}{} & \multicolumn{2}{c|}{$\%$ reaction } & \multicolumn{2}{c|}{$\mathrm{pD}$} \\
\hline Species & $\begin{array}{c}\text { Amino } \\
\text { Acid }\end{array}$ & $\begin{array}{c}2 \\
\text { hours }\end{array}$ & $\begin{array}{c}24 \\
\text { hours }\end{array}$ & $\begin{array}{c}2 \\
\text { hours }\end{array}$ & $\begin{array}{c}24 \\
\text { hours }\end{array}$ \\
\hline \multirow{6}{*}{ [1] } & $\begin{array}{c}\text { N-Ac- } \\
\text { Cys-OMe }\end{array}$ & 12.9 & 55.4 & 6.60 & 6.38 \\
\cline { 2 - 6 } & $\begin{array}{c}\text { N-Z-Glu- } \\
\text { OMe }\end{array}$ & 12.8 & 13.6 & 6.10 & 6.04 \\
\cline { 2 - 6 } & $\begin{array}{c}\text { N-Bz-His- } \\
\text { OMe }\end{array}$ & 0.7 & 8.3 & 7.26 & 7.10 \\
\cline { 2 - 6 } & $\begin{array}{c}\text { N-Ac- } \\
\text { Met-OMe }\end{array}$ & 0.7 & 11.6 & 7.14 & 7.10 \\
\hline \multirow{5}{*}{ [4] } & $\begin{array}{c}\text { N-Ac- } \\
\text { Cys-OMe }\end{array}$ & 30.0 & 77.5 & 7.18 & 6.97 \\
\cline { 2 - 6 } & $\begin{array}{c}\text { N-Z-Glu- } \\
\text { OMe }\end{array}$ & 4.3 & 5.3 & 6.27 & 6.26 \\
\cline { 2 - 6 } & $\begin{array}{c}\text { N-Bz-His- } \\
\text { OMe }\end{array}$ & 1.4 & 23.1 & 7.53 & 7.47 \\
\cline { 2 - 6 } & $\begin{array}{c}\text { N-Ac- } \\
\text { Met-OMe }\end{array}$ & 7.3 & 45.3 & 7.26 & 7.25 \\
\hline
\end{tabular}

\section{Competition experiments for amino-acid binding}

The ${ }^{19} \mathrm{~F}\left\{{ }^{1} \mathrm{H}\right\}$ NMR spectra of complex [1] after 24 hours (where the reaction was essentially at equilibrium) when incubated with $\mathrm{N}$-protected esters of cysteine, glutamic acid, histidine and methionine, are presented in Figure 6 and show metal coordination to all four, distinct amino acid side chains. The preference for cysteine binding is validated through a competition study involving a mixture of all four amino acids which confirms the first direct evidence for the much-asserted claim that ruthenium(II) organometallic complexes preferably bind to sulphur centres in a biological context. The extent of this preference is remarkable, especially when compared to methionine, whose thioether donor group is almost completely outcompeted by cysteine's thiolate. Surprisingly, it also outcompetes histidine under our conditions. The difference in the chemical shift of the aquo species indicates that the $\mathrm{pD}$ after 24 hours of incubation is no longer 7.20 , due to release of protons from amino acid coordination. This change is emphasised in these experiments due to the working $\mathrm{pD}$ being near the $\mathrm{pK}_{\mathrm{a}}$ for the ruthenium aquo species, and this does not distract from the key competition experiments presented in Figure 6.

In principle, of course, one could use high-resolution, ${ }^{1} \mathrm{H}$ NMR data to uncover the speciation we have demonstrated above using ${ }^{19} \mathrm{~F}$ NMR. The enhanced clarity of using ${ }^{19} \mathrm{~F}$ NMR to monitor speciation of ruthenium complexes in complex biological mixtures is demonstrated by comparing the time course ${ }^{19} \mathrm{~F}$ NMR and ${ }^{1} \mathrm{H}$ NMR spectra when complex [1] is incubated with the four protected amino acids in competition as discussed above, Figure S6. The ${ }^{19} \mathrm{~F}$ NMR spectra allow for rapid (32 scans, 2 minute measurement) identification of the number and concentration of different ruthenium species in solution. The ${ }^{1} \mathrm{H}$ NMR spectra are, however, difficult to deconvolute without time consuming 2-D NMR experiments, and peaks often overlap or are co-incident. The data in Figure S6 are for the best-case scenario; for complexes containing any arene ligand other than benzene, ${ }^{1} \mathrm{H}$ NMR data were insufficient, making accurate quantification with temporal resolution impossible. 


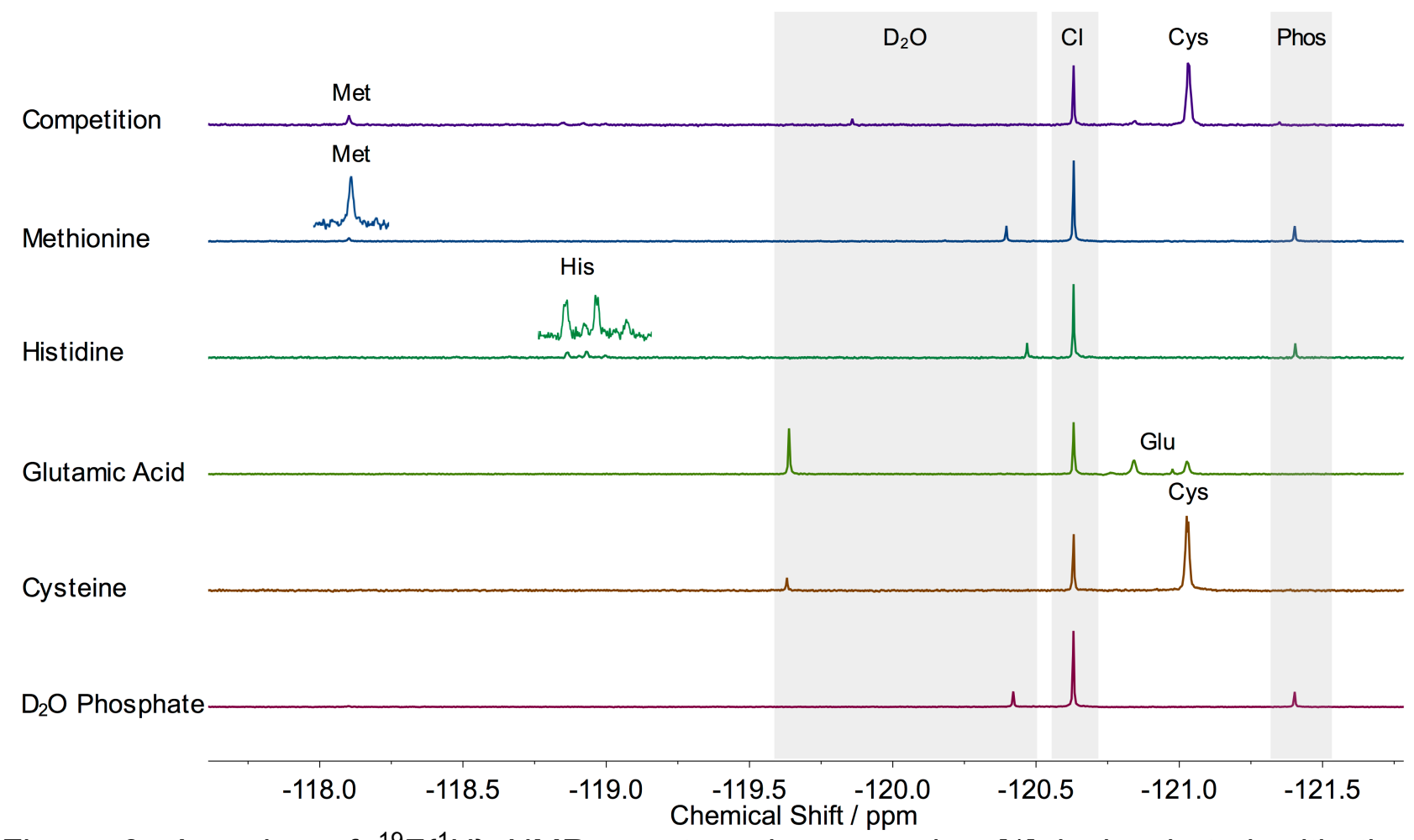

Figure 6: A series of ${ }^{19} \mathrm{~F}\left\{{ }^{1} \mathrm{H}\right\}$ NMR spectra when complex [1] is incubated with the protected amino acids, N-Ac-Cys-OMe, N-Z-Glu-OMe, N-Bz-His-OMe, N-Ac-Met-OMe, and a mixture of all amino acids together, ( $2 \mathrm{mM} \mathrm{Ru}, 3$ eq. each amino acid, $24 \mathrm{hr}, 310 \mathrm{~K})$.

It is worth explaining here that the signals observed from methionine, glutamic acid and histidine coordinated species reveal additional layers of complexity leading to multiple resonances in the ${ }^{19} \mathrm{~F}$ NMR spectra. While the methionine species in Figure 6 generates what looks like a singlet, binding to complexes [2] - [4] gives two doublets of unequal intensity (Figures S7-9). Our interpretation of this is that methionine thioether coordination generates a new chiral centre at the sulphur and the two consequent diastereomers are not formed equally. For histidine coordination the diastereotopic fluorines described above are more obvious, but again two doublets of unequal intensity are observed and this is ascribed to species that differ by coordination through either of the imidazole nitrogens, $\mathrm{N}_{\delta}$ or $\mathrm{N}_{\varepsilon}$.

We have tried to crystallise the amino acid-coordinated complexes in many instances, but the only example that has yielded diffraction quality crystals is that of $\left[\mathrm{Ru}\left(\eta_{6^{-}}\right.\right.$ benzene)(2,2'-bipyridine)( $\mathrm{N}$-acetyl cysteine)][PF 6 ], [13], synthesised from [11] in an excess of cysteine. There is nothing surprising about this particular structure in terms of bond lengths and angles. The crystal lattice is stabilised primarily by $\mathrm{H}$-bonding between the amino acid $\mathrm{NH}$ and $\mathrm{CO}$ groups and water, together with stacking of the bipyridyl rings.

When incubated with $\mathrm{N}$-acetyl cysteine, the ruthenium complex is exposed to nucleophilic attack from both the $\alpha$ carboxylate and thiolate Lewis bases. Interestingly, temporal studies of these samples, show that the carboxylate coordinated species form most rapidly, before being replaced by the thiol coordinated species (Figure S10). The crystal structure reports the preference for metal-thiolate adduct formation in the solid state. The NMR spectroscopy and crystallographic evidence suggest that these ruthenium(II) arene bipyridine complexes form surprisingly stable cysteine adducts in contrast to other 
structurally similar complexes whereby cysteine coordination appears to catalyse further decomposition. ${ }^{44-46}$

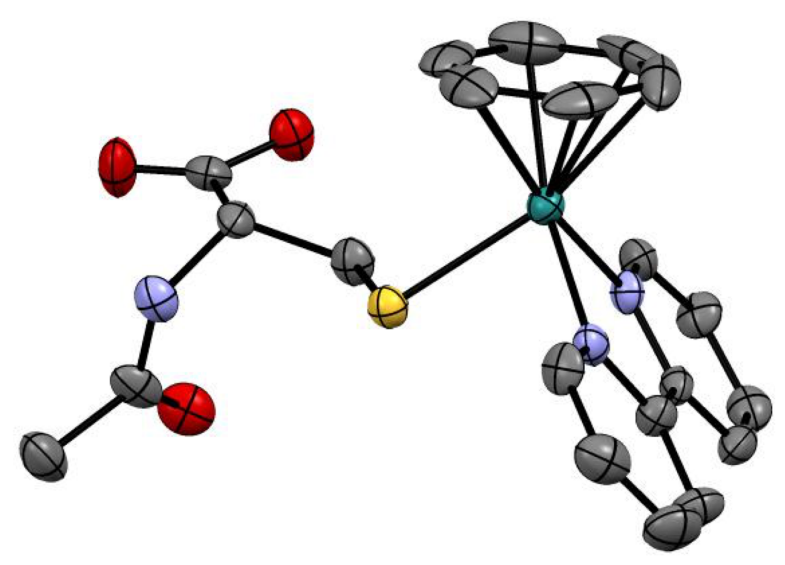

Figure 7: Structure of complex [13] showing displacement ellipsoids at $50 \%$ probability. The counterions, hydrogen atoms and lattice water molecules have been omitted for clarity.

\section{Binding to Glutathione}

Reasoning that complex [1] would bind to cysteine in a cell if presented with the opportunity, we probed its reactivity with the most bioavailable source of cellular cysteine residues: glutathione. The cell redox buffer, glutathione, equilibrates between reduced monomer (GSH, containing a thiol) and oxidized dimer (GSSG, containing a S-S bridge).

Incubating [1] with varying defined mixtures of GSH and GSSG gives ${ }^{19} \mathrm{~F}$ NMR spectra which quantifiably show that binding to the acid groups is preferred in the absence of free thiolate, but that binding to cysteine's thiolate group is markedly thermodynamically preferred in the regimes for which it is available (Figure 8). Complexes [2], [3] and [4] also exhibit preferential thiolate coordination (Figures S11-13). 


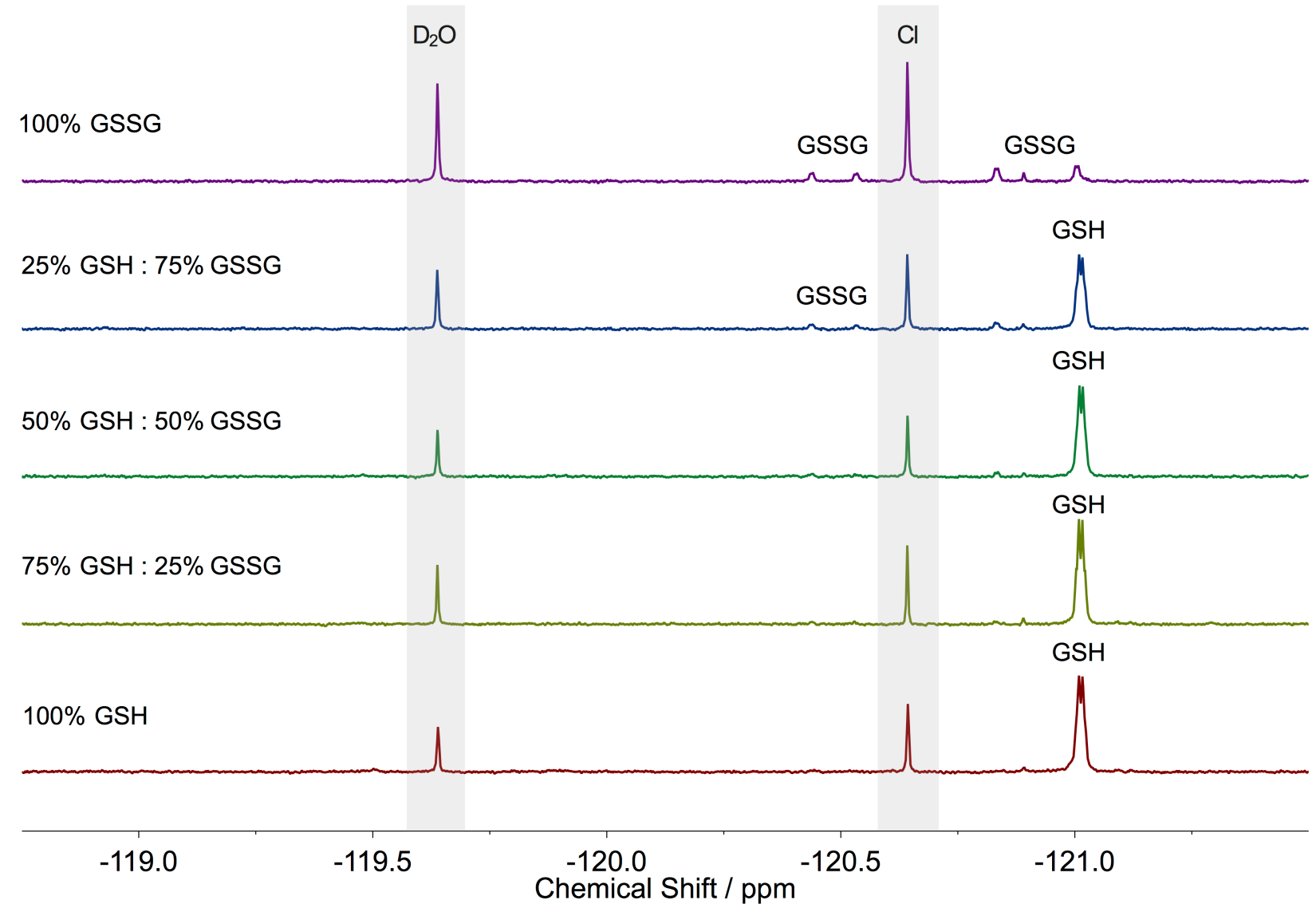

Figure 8: A series of ${ }^{19} \mathrm{~F}\left\{{ }^{1} \mathrm{H}\right\}$ NMR spectra when complex [1] is incubated with defined mixtures of reduced and oxidised glutathione ( $2 \mathrm{mM} \mathrm{Ru}, 3 \mathrm{eq}$. glutathione, $24 \mathrm{hr}, 310 \mathrm{~K})$.

\section{CONCLUSIONS}

${ }^{19} \mathrm{~F}$ NMR spectroscopy has enabled us to undertake a detailed study of a suite of ruthenium organometallic complexes with fluoro-substituted bipyridyl ligands and their ligand exchange behaviour with amino acid side chains. The ${ }^{19} \mathrm{~F}$ NMR spectra provide quantitative information on the reactions of these complexes with amino acid Lewis bases which couldn't be gathered using traditional 1-D ${ }^{1} \mathrm{H}$ NMR (2-D experiments rely on extensive measurement time). Specifically, we can assess the relative binding preferences for each metal complex and track the speciation of the complexes on a relevant time scale. While our question is ultimately to ask whether these or related complexes might report what they are bound to in complex biological mixtures, perhaps even cellular cytoplasm, the complexity of signals even in relatively simple mixtures at moderate concentrations surprised us and this required careful and detailed analysis to ensure that the output from the ${ }^{19} \mathrm{~F}$ NMR could be accurately interpreted.

Of course, the main targets for ruthenium organometallics in cells are likely to be proteins which can provide one or more Lewis basic sidechains at a given site to exchange with the metal. We will extend our ${ }^{19} \mathrm{~F}$ reporter studies to examine speciation following reaction with proteins, but early experiments show that this cannot be generalised for all proteins and results are, unsurprisingly, very protein specific. However, we believe the insight provided by the experiments described above are not just useful, but essential to understand speciation of ruthenium complexes in complex biochemical environments. 


\section{EXPERIMENTAL SECTION}

\section{General Considerations}

When necessary all reactions were kept under an inert atmosphere or under a $\mathrm{N}_{2}$ flow using standard Schlenk line techniques. Methanol (MeOH), acetonitrile ( $\mathrm{MeCN}$ ), dichloromethane (DCM) and other required solvents were dried through distillation, stored over suitable drying agents and purged with $\mathrm{N}_{2}$ before use.

\section{Chemicals and Reagents}

Chemicals and solvents were purchased from chemical suppliers Sigma-Aldrich, Merck, Acros Organic and Insight Biotechnologies.

\section{Physical Measurements}

Mass spectrometry was performed on a Micromass Quattro LC ESI-mass spectrometer. Samples were typically prepared in ultrapure water or 50:50 ultrapure water/acetonitrile. lonization was achieved with a capillary voltage of $2.8 \mathrm{kV}$, cone voltage of $30 \mathrm{~V}$ and a collection voltage of $3 \mathrm{~V}$. Desolvation and capillary temperatures were $323 \mathrm{~K}$.

Single-crystal X-ray diffraction data were collected at $180 \mathrm{~K}$ using either a Nonius KappaCCD or Bruker D8-QUEST diffractometer, equipped with MoK $\alpha$ or CuK $\alpha$ radiation, respectively. Structures were solved using SHELXT ${ }^{47}$ and refined on $\mathrm{F}^{2}$ using SHELXL. ${ }^{48}$

${ }^{1} \mathrm{H},{ }^{13} \mathrm{C},{ }^{19} \mathrm{~F}$ and two-dimensional NMR spectra were collected using a $400 \mathrm{MHz}$ Bruker Avance III. ${ }^{1} \mathrm{H}$ NMR spectra were collected at $400.13 \mathrm{MHz},{ }^{13} \mathrm{C}$ NMR spectra at 100.57 $\mathrm{MHz}$ and ${ }^{19} \mathrm{~F}$ 376.50. All $1 \mathrm{D}{ }^{19} \mathrm{~F}$ NMR spectra were recorded using an inverse gated decoupling pulse programme so that integration values can be quantified. Fluorine COSY experiments were collected using a $400 \mathrm{MHz}$ Bruker QNP Cryoprobe spectrometer.

Elemental $(\mathrm{C}, \mathrm{H}, \mathrm{N})$ analyses were obtained using an Exeter CE-440 Elemental Analyser.

\section{Syntheses}

The detailed syntheses and characterisation of the ruthenium arene dimers, fluorinated bipyridine ligands (A) - (D) and ruthenium complexes [1] - [10] are presented in the supporting information. Representative syntheses of the fluorinated bipyridines and ruthenium bipyridine complexes are as follows:

General Procedure for the synthesis of fluorinated bipyridine ligands (a) - (d).

The starting bromopyridine ( $1 \mathrm{~mol}$ equiv), $\mathrm{Pd}{ }^{\prime \prime}(\mathrm{OAc})_{2}\left(0.025 \mathrm{~mol}\right.$ equiv.), $\mathrm{K}_{2} \mathrm{CO}_{3}$ (1 mol equiv.) and poly(ethylene glycol) ( $\mathrm{Mw} 4000,5.0$ - 10g) were combined in a nitrogen purged flask. This mixture was heated to $120^{\circ} \mathrm{C}$ and the temperature maintained for 48 hours with stirring. The mixture was cooled to $80^{\circ} \mathrm{C}$ and $15 \mathrm{~mL}$ of warm water was added. Once at room temperature a further $10 \mathrm{~mL}$ of water was added and the suspension exhaustively extracted with ethyl acetate. The combined extracts were washed with saturated aqueous $\mathrm{Na}_{2} \mathrm{~S}_{2} \mathrm{O}_{3}$ and three times with brine. The organic layer was then dried over $\mathrm{MgSO}_{4}$ and solvent removed in vacuo. The product was then purified via sublimation.

General Procedure for the Synthesis of Ru complexes 
$\left[\mathrm{RuCl}_{2}\left(\eta_{6} \text {-arene }\right)\right]_{2}(1 \mathrm{~mol}$ equiv. $)$ and (a), (b), (c) or (d) $(2$ mol equiv.) were added to a nitrogen purged flask. Freshly distilled $\mathrm{MeOH}$ was added and the reaction was stirred for 24 hours at room temperature. The contents were filtered under gravity to remove unreacted ruthenium dimer and the solution was reduced to approximately $5 \mathrm{~mL}$ in vacuo. $\mathrm{NH}_{4} \mathrm{PF}_{6}$ (6 mol equiv) was added and the mixture was shaken and left at $-10{ }^{\circ} \mathrm{C}$ for a further 24 hours. The product was collected by gravity filtration as an orange/yellow solid and washed with cold $\mathrm{MeOH}$ and $\mathrm{Et}_{2} \mathrm{O}$. Purification could be achieved through recrystallization from hot $\mathrm{MeOH}$.

Synthesis of [13] - [Ru( 6 6-benzene)(2,2'-bipyridine)(N-acetyl cysteine)][PF6]

In a typical experiment $\mathrm{N}$-Acetyl-Cysteine $(21 \mathrm{mg}, 0.12 \mathrm{mmol})$ was dissolved in water (8 $\mathrm{mL}$ ) and complex [8] (30 mg, $0.058 \mathrm{mmol}$ ) added forming a yellow solution that turned orange after 18 hours. The reaction mixture was stirred at $60^{\circ} \mathrm{C}$ for 72 hours before being cooled to RT and then stored at $4{ }^{\circ} \mathrm{C}$ for 72 hours. The resulting red crystals, suitable for single crystal $\mathrm{X}$-ray diffraction, were collected on the filter and washed with ice cold water $(1 \mathrm{~mL})$ before being dried in vacuo.

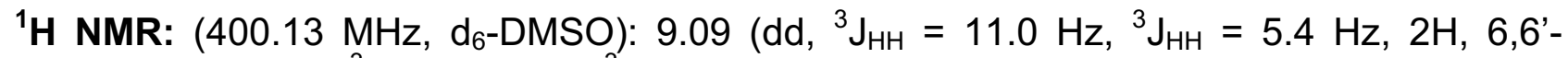
position), 8.33 (dd, ${ }^{3} \mathrm{~J}_{\mathrm{HH}}=8.2 \mathrm{~Hz},{ }^{3} \mathrm{~J}_{\mathrm{HH}}=6.0 \mathrm{~Hz}, 2 \mathrm{H}, 3,3$ '-position), 8.09 (overlapping ddd, ${ }^{3} \mathrm{~J}_{\mathrm{HH}}=8.2 \mathrm{~Hz},{ }^{3} \mathrm{~J}_{\mathrm{HH}}=8.0 \mathrm{~Hz},{ }^{4} \mathrm{~J}_{\mathrm{HH}}=5.4 \mathrm{~Hz}, 2 \mathrm{H}, 4,4$ '-position), 7.79 (overlapping ddd, ${ }^{3} \mathrm{~J}_{\mathrm{HH}}$ $=11.0 \mathrm{~Hz},{ }^{3} \mathrm{~J}_{\mathrm{HH}}=8.0 \mathrm{~Hz},{ }^{3} \mathrm{~J}_{\mathrm{HH}}=6.0 \mathrm{~Hz}, 2 \mathrm{H}, 5,5$-position), $5.95(\mathrm{~s}, 6 \mathrm{H}, \mathrm{PhH}), 3.74(\mathrm{~m} ; 1 \mathrm{H}$ $\left.\mathrm{N}-\mathrm{Ac}-\mathrm{Cys}-\mathrm{C}^{*} \mathrm{H},\right), 2.12\left(\mathrm{~m} ; 2 \mathrm{H} ; \mathrm{N}-\mathrm{Ac}-\mathrm{Cys}-\mathrm{CH}_{2}\right), 1.75\left(\mathrm{~s} ; 3 \mathrm{H} ; \mathrm{N}-\mathrm{Ac}-\mathrm{Cys}-\mathrm{CH}_{3}\right) .{ }^{13} \mathrm{C}\left\{{ }^{1} \mathrm{H}\right\}$ NMR: (100.57 MHz, D ${ }_{2} \mathrm{O}$ ): 174.2, 173.3 (N-Ac-Cys- $\left.\mathrm{CH}_{3} \mathrm{CONH}-+\mathrm{N}-\mathrm{Ac}-\mathrm{Cys}-\mathrm{COOH}\right), 155.2$ (6,6'position, 154.7 (2,2'-position), 139.5 (4,4'-position) 127.2 (5,5'-position), 123. (3,3'position), $88.5(\mathrm{PhH}), 54.7\left(\mathrm{~N}-\mathrm{Ac}-\mathrm{Cys}-\mathrm{C}^{*} \mathrm{H}\right), 29.2\left(\mathrm{~N}-\mathrm{Ac}-\mathrm{Cys}-\mathrm{CH}_{2}\right), 21.4\left(\mathrm{~N}-\mathrm{Ac}-\mathrm{Cys}-\mathrm{CH}_{3},\right)$. IR: $\mathrm{v}(\mathrm{N}-\mathrm{H}) 3648(\mathrm{~m}) ;(\mathrm{X}-\mathrm{H})$ multiple weak signals around 3000; $(\mathrm{C}=\mathrm{O}$ acid $) 1735(\mathrm{~m}) ;(\mathrm{C}=\mathrm{O}$ amide) 1607 (s); (arene stretches) 1471 (m) \& 1445 (s); (arene bends) 837 (s), 820 (s), 763 (s) \& 726 (m). LR-MS: $\left(\mathrm{ESI}^{+} \mathrm{m} / \mathrm{z} 498.0\right.$ (singly charged, [Ru( $\eta^{6}$-benzene)(2,2'bipyridine $)(\mathrm{N}$-acetyl-cysteine $\left.)]^{+}\right)$.

\section{$p K_{a}$ Measurements}

$10 \mathrm{mM}$ deuterated phosphate buffer solution was prepared using potassium dihydrogen orthophosphate in $\mathrm{D}_{2} \mathrm{O}$ and adjusted to different $\mathrm{pD}$ values in the range of 4.7 to 11.2 using $1 \mathrm{~N} \mathrm{NaOD.} \mathrm{The} \mathrm{different} \mathrm{buffers} \mathrm{were} \mathrm{then} \mathrm{incubated} \mathrm{with} \mathrm{Complexes} \mathrm{[1]} \mathrm{-} \mathrm{[4],} \mathrm{[10]}$ and [11] for 2 hours at $298 \mathrm{~K}$ and ${ }^{1} \mathrm{H}$ and ${ }^{19} \mathrm{~F}\left\{{ }^{1} \mathrm{H}\right\}$ NMR spectra recorded. All ${ }^{19} \mathrm{~F}\left\{{ }^{1} \mathrm{H}\right\}$ NMR spectra recorded are 32 scans. $\mathrm{pD}$ values are corrected $\mathrm{pH}$ meter readings.

\section{Biomolecule interactions}

The incubations between ruthenium and amino acids were performed in either a 1.5 or 3 molar excess of amino acid/ glutathione. Ruthenium complexes were dissolved in $1 \%$ DMF and diluted with a solution of amino acid in $\mathrm{D}_{2} \mathrm{O}$ phosphate buffer $\mathrm{pD}=7.2 .{ }^{19} \mathrm{~F}\left\{{ }^{1} \mathrm{H}\right\} \mathrm{NMR}$ spectra were recorded at 2, 4, 8 and 24 hours, with mass spectra recorded at 8 and 24 hours. All ${ }^{19} \mathrm{~F}\left\{{ }^{1} \mathrm{H}\right\}$ NMR spectra recorded are 32 scans.

\section{ASSOCIATED CONTENT}

\section{Supporting Information}

Experimental procedures and spectral data for all new compounds, together with details of the X-ray structures of complexes [1] -[10]. 
The Supporting Information is available free of charge on the ACS Publications website.

Accession Codes

CCDC 1867661-1867671 contain the supplementary crystallographic data for this paper. These data can be obtained free of charge via www.ccdc.cam.ac.uk/data_request/cif, or by emailing data_request@ccdc.cam.ac.uk, or by contacting The Cambridge Crystallographic Data Centre, 12 Union Road, Cambridge CB2 1EZ, UK; fax: +44 1223 336033.

\section{AUTHOR INFORMATION}

Corresponding Authors

*Email (PDB): pdb30@cam.ac.uk, (SRB): srb39@cam.ac.uk

ORCID

George S. Biggs: 0000-0001-6526-9236

Michael J. O'Neill: 0000-0001-5224-9121

Andrew D. Bond: 0000-0002-1744-0489

Sally R. Boss: 0000-0002-6194-1889

Paul Barker: 0000-0003-0094-0054

Present Addresses

TGS Johnson Matthey plc, 28 Cambridge Science Park, Milton Road Cambridge CB4 OFP, UK

PCM: School of Chemistry, University of Leeds, Leeds LS2 9JT UK

Author contributions

GSB and MJO contributed equally to this project. MJO had the original idea; MJO, GSB, TGS, YL, SRB and PDB designed experiments; GSB, MJO, TGS, PCM, AMBM, and YL carried out experimental work; ADB collected X-ray diffraction data and solved the structures; all authors analysed experimental data; GSB, MJO, PDB and SRB wrote the manuscript.

Notes

The authors declare no competing financial interest.

\section{ACKNOWLEDGMENT}

TGS and MJO were supported by EPSRC studentships (EP/P505445/1 and EP/K503009/1) and GSB was supported by the EPRSC (EP/N509620/1) and Peterhouse, Cambridge. We thank the staff of the Chemistry Department NMR facility for help and advice.

\section{REFERENCES}


1 J. F. Wishart, H. Taube, K. J. Breslauer and S. S. Isied, Inorg. Chem., 1984, 23, 2997-3001.

2 M. J. Clarke, Coord. Chem. Rev., 2002, 232, 69-93.

3 I. D. Kuntz, K. Chen, K. A. Sharp and P. A. Kollman, Proc. Natl. Acad. Sci. U. S. A., 1999, 96, 9997-10002.

4 C. Artner, H. U. Holtkamp, C. G. Hartinger and S. M. Meier-Menches, J. Inorg. Biochem., 2017, 177, 322-327.

5 S. M. Meier, M. Hanif, W. Kandioller, B. K. Keppler and C. G. Hartinger, J. Inorg. Biochem., 2012, 108, 91-5.

6 S. Movassaghi, S. Singh, A. Mansur, K. K. H. Tong, M. Hanif, H. U. Holtkamp, T. Söhnel, S. M. F. Jamieson and C. G. Hartinger, Organometallics, 2018, 37, 15751584.

7 M. Groessl, E. Reisner, C. G. Hartinger, R. Eichinger, O. Semenova, A. R. Timerbaev, M. A. Jakupec, V. B. Arion and B. K. Keppler, J. Med. Chem., 2007, 50, 2185-2193.

8 R. Trondl, P. Heffeter, C. R. Kowol, M. A. Jakupec, W. Berger, B. K. Keppler, J. C. Bendell, A. Ogden, D. D. Von Hoff, U. Jaehde, R. Stoika, A. Zaichenko and W. Berger, Chem. Sci., 2014, 5, 2925-2932.

9 M. Groessl, O. Zava and P. J. Dyson, Metallomics, 2011, 3, 591-599.

10 S. M. Meier-Menches, C. Gerner, W. Berger, C. G. Hartinger and B. K. Keppler, Chem. Soc. Rev., 2018, 47, 909-928.

11 P. Zhang and P. J. Sadler, J. Organomet. Chem., 2017, 839, 5-14.

12 A. A. Nazarov, C. G. Hartinger and P. J. Dyson, J. Organomet. Chem., 2014, 751, 251-260.

13 A. L. Noffke, A. Habtemariam, A. M. Pizarro and P. J. Sadler, Chem. Commun., 2012, 48, 5219-5246.

14 M. Kubanik, W. Kandioller, K. Kim, R. F. Anderson, E. Klapproth, M. A. Jakupec, A. Roller, T. Söhnel, B. K. Keppler and C. G. Hartinger, Dalt. Trans., 2016, 45, 1309113103.

15 T. G. Scrase, M. J. Oneill, A. J. Peel, P. W. Senior, P. D. Matthews, H. Shi, S. R. Boss and P. D. Barker, Inorg. Chem., 2015, 54, 3118-3124.

16 J. M. Cross, N. Gallagher, J. H. Gill, M. Jain, A. W. McNeillis, K. L. Rockley, F. H. Tscherny, N. J. Wirszycz, D. S. Yufit and J. W. Walton, Dalt. Trans., 2016, 45, 12807-12813.

17 M. V. Babak, S. M. Meier, K. V. M. Huber, J. Reynisson, A. A. Legin, M. A. Jakupec, A. Roller, A. Stukalov, M. Gridling, K. L. Bennett, J. Colinge, W. Berger, P. J. Dyson, G. Superti-Furga, B. K. Keppler and C. G. Hartinger, Chem. Sci., 2015, 6, 24492456. 
18 B. Wu, M. S. Ong, M. Groessl, Z. Adhireksan, C. G. Hartinger, P. J. Dyson and C. A. Davey, Chem. Eur. J., 2011, 17, 3562-6.

19 Z. Adhireksan, G. E. Davey, P. Campomanes, M. Groessl, C. M. Clavel, H. Yu, A. A. Nazarov, C. H. F. Yeo, W. H. Ang, P. Dröge, U. Rothlisberger, P. J. Dyson and C. A. Davey, Nat. Commun., 2014, 5, 1387-1407.

20 Z. Ma, G. Palermo, Z. Adhireksan, B. S. Murray, T. von Erlach, P. J. Dyson, U. Rothlisberger and C. A. Davey, Angew. Chemie - Int. Ed., 2016, 55, 7441-7444.

21 B. J. Reedijk, Platin. Met. Rev., 2008, 52, 2-11.

22 C. G. Hartinger, M. Groessl, S. M. Meier, A. Casini and P. J. Dyson, Chem. Soc. Rev., 2013, 42, 6186.

23 A. Casini, G. Mastrobuoni, W. H. H. Ang, C. Gabbiani, G. Pieraccini, G. Moneti, P. J. J. Dyson and L. Messori, ChemMedChem, 2007, 2, 631-635.

24 C. Artner, H. U. Holtkamp, W. Kandioller, C. G. Hartinger, S. M. Meier-Menches, B. K. Keppler, A. A. Nazarov, C. H. Yeo, W. H. Ang and P. Droge, Chem. Commun., 2017, 5, 3462.

25 I. W. McNae, K. Fishburne, A. Habtemariam, T. M. Hunter, M. Melchart, F. Wang, M. D. Walkinshaw, P. J. Sadler, G. Boyd, D. I. Jodrell and P. J. Sadler, Chem. Commun., 2004, A47, 1786-1787.

26 M. P. Sullivan, M. Groessl, S. M. Meier, R. L. Kingston, D. C. Goldstone, C. G. Hartinger, T. Sohnel, S. M. F. Jamieson, C. G. Hartinger, W. Weigand, J. Colinge, W. Berger, P. J. Dyson, G. Superti-Furga, B. K. Keppler and C. G. Hartinger, Chem. Commun., 2017, 53, 4246-4249.

27 C. A. Smith, A. J. Sutherland-Smith, F. Kratz, E. N. Baker and B. H. Keppler, J. Biol. Inorg. Chem., 1996, 1, 424-431.

28 G. K. Radda, Science, 1986, 233, 640-645.

29 J. M. Salhany, T. Yamane, R. G. Shulman and S. Ogawa, Proc. Natl. Acad. Sci. U. S. A., 1975, 72, 4966-70.

30 R. G. Shulman, T. R. Brown, K. Ugurbil, S. Ogawa, S. M. Cohen and J. A. den Hollander, Science, 1979, 205, 160-6.

31 K. H. Gardner and L. E. Kay, Annu. Rev. Biophys. Biomol. Struct., 1998, 27, 357406.

32 H. Chen, S. Viel, F. Ziarelli and L. Peng, Chem. Soc. Rev., 2013, 42, 7971-82.

33 Y. Suzuki, Chem. Biol., 2014, 9, 1242-1250.

34 C. Dalvit and A. Vulpetti, J. Med. Chem., 2018.

35 C. Dalvit, Prog. Nucl. Magn. Reson. Spectrosc., 2007, 51, 243-271.

36 Z. Xu, H. M. Chan, C. Li, Z. Wang, M. K. Tse, Z. Tong and G. Zhu, Inorg. Chem., 2018, 57, 8227-8235. 
37 K. Lee and P. H. Lee, Tetrahedron Lett., 2008, 49, 4302-4305.

38 M. Furue, K. Maruyama, T. Oguni, M. Naiki and M. Kamachi, Inorg. Chem, 1992, 31, 3792-3795.

39 L. Wang, Y. Zhang, L. Liu and Y. Wang, J. Org. Chem., 2006, 71, 1284-1287.

40 Y. Lin, University of Cambridge, MPhil Thesis, 2016.

41 H. Chen, J. A. Parkinson, R. E. Morris and P. J. Sadler, J. Am. Chem. Soc., 2003, $125,173-186$.

42 A. K. Renfrew, A. D. Phillips, E. Tapavicza, R. Scopelliti, U. Rothlisberger and P. J. Dyson, Organometallics, 2009, 28, 5061-5071.

43 S. J. Pike, M. De Poli, W. Zawodny, J. Raftery, S. J. Webb and J. Clayden, Org. Biomol. Chem., 2013, 11, 3168-3176.

44 W. Kandioller, A. Kurzwernhart, M. Hanif, S. M. Meier, H. Henke, B. K. Keppler and C. G. Hartinger, J. Organomet. Chem., 2011, 696, 999-1010.

45 M. Hanif, S. M. Meier, Z. Adhireksan, H. Henke, S. Martic, S. Movassaghi, M. Labib, W. Kandioller, S. M. F. Jamieson, M. Hejl, M. A. Jakupec, H.-B. Kraatz, C. A. Davey, B. K. Keppler and C. G. Hartinger, Chempluschem, 2017, 82, 841-847.

46 S. Movassaghi, M. Hanif, H. U. Holtkamp, T. Söhnel, S. M. F. Jamieson and C. G. Hartinger, Dalt. Trans., 2018, 47, 2192-2201.

47 G. M. Sheldrick, Acta Crystallogr. Sect. A, 2015, 71, 3-8.

48 G. M. Sheldrick, Acta Crystallogr. Sect. C, 2015, 71, 3-8. 